\title{
A RETROSPECTIVE STUDY OF ROLE OF HYSTEROLAPAROSCOPY IN THE EVALUATION OF FEMALE INFERTILITY, IN 100 PATIENTS IN A PRIVATE HOSPITAL OVER A PERIOD OF TWO YEARS
}

\author{
Krishnaveni Avula1, Mahalaxmi G², Sushruth Kumar Arige3 ${ }^{3}$ Subodh Kumar Arige ${ }^{4}$ \\ ${ }^{1}$ Assistant Professor, Department of Obstetrics and Gynaecology, Gandhi Medical College. \\ 2Professor, Department of Obstetrics and Gynaecology, Gandhi Medical College. \\ ${ }^{3} 2^{\text {nd }}$ Year Medical Student, Gandhi Medical College. \\ ${ }^{4}$ Professor, Department of Plastic Surgery, Gandhi Medical College.
}

\section{ABSTRACT}

\section{BACKGROUND}

Infertility affects up to $15 \%$ of couples. The routine pelvic examination and diagnostic procedures are not sufficient in the evaluation. Hysteroscopy allows the uterine cavity to be visualised, while laparoscopy enables that of uterus, tubes and ovaries.

The aim of this study is to analyse the causes of primary and secondary infertility through hysteroscopy and laparoscopy, and their therapeutic role.

\section{MATERIALS AND METHODS}

A retrospective study was done at Shreshta Sushruth hospital on 100 patients aged between 20-35 years who underwent hysterolaparoscopy for infertility between 2015 and 2016. Study excluded patients with hormonal abnormalities and couples with abnormal semen analysis. The case records were examined, data pooled and analysed.

\section{RESULTS}

$72 \%$ women had primary infertility and $28 \%$ had secondary infertility. $48 \%$ with infertility were between $25-30$ years of age. $57 \%$ and $12 \%$ with primary infertility had abnormal laparoscopic and hysteroscopic findings respectively. Polycystic ovarian disease (48\%) and tubal block (32\%) were the common laparoscopic abnormalities while uterine septum (17\%), myomas (17\%) and hyperplastic endometrium (41\%) were the common hysteroscopy abnormalities in the infertility cases. Amongst cases with primary infertility, polycystic ovarian disease (50\%) was common and amongst those with secondary infertility, bilateral tubal block (46\%) was seen frequently. All the cases of primary infertility with polycystic ovarian disease were subjected to ovarian drilling and thorough wash and they all conceived. Among 32 patients of tubal block, 24/32 (75\%) had positive dye test after appropriate intervention and among them $36 \%$ patients conceived within three months. $62 \%$ had successful pregnancy.

\section{CONCLUSION}

Hysterolaparoscopy has been found to be an effective, safe diagnostic tool in the evaluation of the causes of female infertility in the uterus, tubes, fimbriae, ovaries without any major complications and it has a therapeutic role for application in the same sitting, enabling ovarian drilling, tubal cannulation, fimbrioplasty, adhesiolysis, uterine septal resection, excision of chocolate cysts, cauterisation of endometrial spots, etc., and thus facilitating conception.

\section{KEYWORDS}

Hysteroscopy, Laparoscopy, Diagnostic, Therapeutic, Primary Infertility, Secondary Infertility.

HOW TO CITE THIS ARTICLE: Avula K, Mahalaxmi G, Arige SK, et al. A retrospective study of the role of hysterolaparoscopy in the evaluation of female infertility, in 100 patients in a private hospital over a period of two years. J. Evolution Med. Dent. Sci. 2017;6(52):3955-3958, DOI: 10.14260/Jemds/2017/856

\section{BACKGROUND}

Infertility is a problem in up to $15 \%$ of married people. Pelvic examination and routine diagnostic procedures do not reveal the pelvic pathology in a majority of infertile women. Visualisation of the uterus, fallopian tubes, ovaries has been made possible by the laparoscopy, and hysteroscopy has enabled the uterine cavity to be seen. Both of them together have made it possible for the tubal, ovarian, uterine and pelvic pathologies to be diagnosed and enabled some therapeutic procedures like adhesiolysis, myomectomy, polypectomy, etc., to be undertaken in the same sitting.

Financial or Other, Competing Interest: None.

Submission 23-05-2017, Peer Review 23-06-2017,

Acceptance 15-06-2017, Published 29-06-2017.

Corresponding Author:

Dr. Krishnaveni Avula,

\#13-6-457/29,

Gayatrinagar, Shivbagh, Near Gudimalkapur

Vegetable Market, Hyderabad-500006, Telangana.

E-mail: akveni1010@gmail.com

DOI: $10.14260 /$ jemds $/ 2017 / 856$

\section{Aim}

To study the role of hysterolaparoscopy in female infertility.

\section{Objectives}

To analyse the common causes in Primary and Secondary infertility through Hysteroscopy and through Laparoscopy.

\section{MATERIALS AND METHODS}

This retrospective study was conducted at Shreshta Sushruth Hospital between January 2015 and December 2016, on 100 patients, aged between 20-35 years who presented with either primary or secondary infertility of more than one-year duration and they were subjected to hysterolaparoscopy. The case records were examined, data pooled and analysed. Patients were subjected to surgery under general anaesthesia. Tablet Misoprostol $200 \mathrm{mg}$ was placed in the vaginal cavity in the posterior fornix, six hours before surgery for cervical dilatation. Hysteroscopy was done with the patient in lithotomy position and the findings were noted, especially the cervical canal, uterine cavity, uterine walls, and 
the ostia of the tubes were looked at. The patient was then put in head low position, and laparoscopy was done, using 10 $\mathrm{mm}$ port for the scope and another two $5 \mathrm{~mm}$ ports for the manipulations. The uterus, tubes, ovaries, pouch of Douglas were examined. Methylene blue dye was pushed through the cervix and its spillage into the peritoneal cavity through the fallopian tube openings was noted. Polycystic ovaries, were subjected to drilling at 4-6 sites and it was done using cautery through the $5-\mathrm{mm}$ port. Necessary intervention was done according to the abnormal finding like hysteroscopic septal resection, excision of chocolate cysts, removal of adhesions, etc. Wash was given with saline and suction done. Endometrial biopsy was taken. The nearby viscera were examined to rule out any accidental injury. Patient was placed in supine position and later extubated, after removal of instruments, evacuation of pneumoperitoneum, removal of trocars and suturing of port sites. Primary infertility patients were those who have never conceived before, while secondary infertility had at-least one prior conception, irrespective of the outcome. Hormonal abnormalities like hyperthyroidism/hypothyroidism,

hyper/hypoprolactinaemia and couples with abnormal semen analysis were not included in this study. Diagnostic Hysterolaparoscopy with chromopertubation test was performed in the early follicular phase in all the patients between $8^{\text {th }}$ and $10^{\text {th }}$ postmenstrual days.

\section{RESULTS}

Out of 100 patients, $72 \%$ women had primary infertility and $28 \%$ women had secondary infertility.

\begin{tabular}{|c|c|c|c|}
\hline $\begin{array}{c}\text { Age } \\
\text { Group }\end{array}$ & $\begin{array}{c}\text { Number } \\
\mathbf{( 1 0 0 )}\end{array}$ & $\begin{array}{c}\text { Primary } \\
\text { Infertility } \\
\text { n (\%) }\end{array}$ & $\begin{array}{c}\text { Secondary } \\
\text { Infertility n (\%) }\end{array}$ \\
\hline $20-25$ yrs. & 18 & $16(89 \%)$ & $2(11 \%)$ \\
\hline $25-30$ yrs. & 48 & $36(75 \%)$ & $12(25 \%)$ \\
\hline $30-35$ yrs. & 34 & $20(59 \%)$ & $14(41 \%)$ \\
\hline \multicolumn{3}{|c}{ Table 1. Age wise Distribution of Female Infertility } \\
\hline
\end{tabular}

Most common affected age group was 25-30 years and amounted to $48 \%$.

\begin{tabular}{|c|c|c|c|c|}
\hline Procedure & \multicolumn{2}{|c|}{ Primary infertility } & \multicolumn{2}{c|}{ Secondary infertility } \\
\hline & $\begin{array}{c}\text { Normal } \\
\mathrm{n}(\%)\end{array}$ & $\begin{array}{c}\text { Abnormal } \\
\mathrm{n}(\%)\end{array}$ & $\begin{array}{c}\text { Normal } \\
\mathrm{n}(\%)\end{array}$ & $\begin{array}{c}\text { Abnormal } \\
\mathrm{n}(\%)\end{array}$ \\
\hline Laparoscopy & $31(43 \%)$ & $41(57 \%)$ & $17(60 \%)$ & $11(40 \%)$ \\
\hline Hysteroscopy & $63(88 \%)$ & $9(12 \%)$ & $3(10 \%)$ & $25(90 \%)$ \\
\hline Total & $94(65 \%)$ & $50(35 \%)$ & $20(36 \%)$ & $36(64 \%)$ \\
\hline Table 2. Normal and abnormal Hysteroscopic and \\
Laparoscopic Findings \\
\hline
\end{tabular}

In the Primary infertility group, $57 \%$ had laparoscopic abnormalities, $12 \%$ had abnormalities on hysteroscopy while, in Secondary infertility group, $40 \%$ had abnormalities in Laparoscopy and 90\% had abnormalities in Hysteroscopy.

\begin{tabular}{|c|c|c|c|}
\hline Findings & $\begin{array}{c}\text { Primary } \\
\text { Infertility }\end{array}$ & $\begin{array}{c}\text { Secondary } \\
\text { Infertility }\end{array}$ & Total \\
\hline Myoma & $3(4 \%)$ & $2(7 \%)$ & 5 \\
\hline Adenomyosis & $1(1 \%)$ & $2(7 \%)$ & 3 \\
\hline Endometriosis & $8(11 \%)$ & $3(10 \%)$ & 11 \\
\hline Uterine anomalies & $5(7 \%)$ & $2(7 \%)$ & 7 \\
\hline Adnexal adhesions & $4(5 \%)$ & $8(28 \%)$ & 12 \\
\hline
\end{tabular}

\begin{tabular}{|c|c|c|c|}
\hline Ovarian cyst & $3(4 \%)$ & $4(14 \%)$ & 7 \\
\hline $\begin{array}{c}\text { Polycystic Ovarian } \\
\text { Disease }\end{array}$ & $36(50 \%)$ & $12(42 \%)$ & 48 \\
\hline Unilateral tubal block & $8(11 \%)$ & $6(21 \%)$ & 14 \\
\hline Bilateral tubal block & $5(7 \%)$ & $13(46 \%)$ & 18 \\
\hline
\end{tabular}

Table 3. Laparoscopic Findings

The most common abnormality in laparoscopy in our study in Primary Infertility was polycystic ovarian disease $(50 \%)$ and in Secondary infertility it was bilateral tubal block (46\%). Few patients had more than two abnormal findings.

\begin{tabular}{|c|c|c|c|}
\hline Findings & $\begin{array}{c}\text { Primary } \\
\text { Infertility }\end{array}$ & $\begin{array}{c}\text { Secondary } \\
\text { Infertility }\end{array}$ & Total \\
\hline $\begin{array}{c}\text { Submucous } \\
\text { myoma }\end{array}$ & $2(3 \%)$ & $2(7 \%)$ & $4(17 \%)$ \\
\hline Polyps & $2(3 \%)$ & $4(14 \%)$ & $6(18 \%)$ \\
\hline Septum & $3(4 \%)$ & $1(4 \%)$ & $4(17 \%)$ \\
\hline Syncytia & 0 & $1(4 \%)$ & $1(3 \%)$ \\
\hline $\begin{array}{c}\text { Atrophic } \\
\text { endometrium }\end{array}$ & 0 & $5(18 \%)$ & $5(15 \%)$ \\
\hline $\begin{array}{c}\text { Hyperplastic } \\
\text { endometrium }\end{array}$ & $2(2 \%)$ & $12(43 \%)$ & $14(41 \%)$ \\
\hline Foreign body & 0 & 0 & 0 \\
\hline \multicolumn{4}{|c|}{ Table 4. Hysteroscopic Findings } \\
\hline
\end{tabular}

In hysteroscopy, 66\% had normal findings and the rest $34 \%$ had abnormal findings.

\begin{tabular}{|c|c|c|c|}
\hline Site & $\begin{array}{c}\text { Primary } \\
\text { Infertility } \\
\text { Number of } \\
\text { Patients }\end{array}$ & $\begin{array}{c}\text { Secondary } \\
\text { Infertility } \\
\text { Number of } \\
\text { Patients }\end{array}$ & $\begin{array}{c}\text { Total No. } \\
\text { of Patients }\end{array}$ \\
\hline Cornual & 2 & 4 & 6 \\
\hline Mid-portion & 4 & 6 & 10 \\
\hline Fimbrial block & 7 & 9 & 16 \\
\hline \multicolumn{3}{|c|}{ Table 5. Sites of Tubal Block } \\
\hline
\end{tabular}

\begin{tabular}{|c|c|c|c|}
\hline Procedure & $\begin{array}{c}\text { Primary } \\
\text { Infertility }\end{array}$ & $\begin{array}{c}\text { Secondary } \\
\text { Infertility }\end{array}$ & $\begin{array}{c}\text { Total } \\
\text { Number of } \\
\text { Patients }\end{array}$ \\
\hline $\begin{array}{c}\text { Repeated } \\
\text { chromotubation }\end{array}$ & 5 & 6 & 11 \\
\hline $\begin{array}{c}\text { Fimbrial } \\
\text { cannulation }\end{array}$ & 3 & 7 & 10 \\
\hline Fimbrioplasty & 1 & 2 & 3 \\
\hline $\begin{array}{c}\text { Total number of } \\
\text { patients }\end{array}$ & 9 & 15 & 24 \\
\hline $\begin{array}{c}\text { Table 6. Positive Dye Test in Tubal Block after Repeated } \\
\text { Chromotubation, Fimbrioplasty, Fallopian Tubal } \\
\text { Cannulation }\end{array}$ \\
\hline
\end{tabular}

Out of 100 patients, 32 patients had tubal block and among them 24 patients have shown positive dye test.

\section{RESULTS}

We had 50\% incidence of polycystic ovarian syndrome (PCOS) amongst those with Primary Infertility and $42 \%$ amongst those with Secondary Infertility with the overall being $48 \%$.

The frequency of tubal occlusion was in $18 \%$ of cases of Primary infertility and in $68 \%$ in cases of secondary infertility. Our present study has shown Pelvic inflammatory 
disease and tubal blockage were more frequently found in secondary infertility as compared to primary infertility.

Among 100 patients, 32 had tubal block and amongst them $24(75 \%)$ cases have shown positive dye test after the appropriate interventions like repeated chromotubation test, fimbrial cannulation, fimbrioplasty, 5 cases were associated with adnexal adhesions, endometriosis grade 3-4 with bowel adhesions.

$17 \%$ of cases in our study had uterine septum and septal resection was done for all those four cases. Among them one patient conceived after 4 months and another patient conceived after six months therapy with oestrogen and progesterone though the patient had irregular and prolonged cycles.

Other than hyperplastic endometrium and septate uterus, the major hysteroscopy abnormalities in our study were myomas and polyps.

Out of 100 patients with infertility, $62 \%$ of patients had successful pregnancy. Out of 24 patients with positive dye test, after intervention for Tubal block, through Hysterolaparoscopy, 21 cases conceived. Two septal resected cases, six patients with endometriosis, who underwent excision of chocolate cysts and cauterisation of endometriotic spots also conceived successfully.

\section{DISCUSSION}

With increasing age, fertility in women declines; however, there is no universal definition of an advanced reproductive age for women, because the effects of increasing age occur as a continuum rather than as a threshold effect and declining fertility is an individual event that differs in each woman.

$40 \%$ women with polycystic ovarian syndrome (PCOS) have Infertility. Tubal and peritubal disease accounts for 15$20 \%$ of cases of primary infertility and $40 \%$ of secondary infertility.[1,2,3] The gold standard technique for diagnosing these disorders is laparoscopy, which is a better predictor of future spontaneous pregnancy in infertile couples with unexplained infertility.[4] Laparoscopic Polycystic ovarian drilling and thorough pelvic wash enabled conception amongst most infertile females with unexplained infertility. Jayakrishnan et al[5] from India detected pelvic pathology in $26.8 \%$ cases of infertile patients by laparoscopic evaluation. We got similar result wherein pelvic pathology was seen in $30 \%$ in our study. In addition, endometriosis and adnexal adhesions were the two major abnormalities found among infertile patients in different studies.[6,7] Similar finding was noted in our study. In contrast to the Study by Godinjak et al,[6] we got equal incidence of tubal block in both groups of infertility patients.

Hysteroscopy is good at treatment of proximal obstruction of fallopian tube and laparoscopy is good at treatment of peri-tubal adhesions and hydrosalpinx.

Uterine pathologies are the cause of infertility in as many as $15 \%$ of couples seeking treatment ${ }^{[8]}$ and are diagnosed in as many as $50 \%$ of infertile patients. $[9,10,11]$ Developmental uterine anomalies have long been associated with pregnancy loss and obstetric complications, but the ability to conceive is generally not affected.

Septate uterus was the most common intrauterine abnormality in our study, which was undiagnosed by prior ultrasonography. The pooled data suggests that the incidence of septate uterus is similar in infertile and fertile women (approximately 1\%), but is significantly higher in women with recurrent pregnancy loss (approximately 3.5\%).[12] Among all congenital uterine abnormalities, septate uterus is the most common cause associated with highest reproductive failure rates.[12,13] Although a diagnosis of septate uterus per se is not an indication for septoplasty, the reproductive performance of women with an uncorrected septum is rather poor $(80 \%$ pregnancy loss, $10 \%$ preterm delivery, $10 \%$ term delivery) with most losses occurring in the first trimester (approximately 65\%). Pregnancy outcomes dramatically improved after surgical correction (80\% term delivery, 5\% preterm delivery, $15 \%$ pregnancy loss).[12] Previously, surgical correction of septate uterus was requiring an abdominal metroplasty, which was associated with increased morbidity and future pregnancy complications due to scarred uterus. Currently, the modern operative hysteroscopic techniques have made it a relatively easy and brief day care procedure with low morbidity and prompt recovery. Therefore, septal resection is recommended more liberally nowadays.

Other than septate uterus, the major hysteroscopy abnormalities in our study were myomas and polyps similar to another study.[14] The evidence to suggest that uterine myomas decrease fertility is inferential and relatively weak; the bulk of it is derived from studies that had compared the incidence of myomas in fertile and infertile women or the reproductive performance of women with otherwise unexplained infertility before and after myomectomy[15, 16]. Proposed mechanisms by which myomas might adversely affect fertility include cornual myomas that involve or compress the interstitial segment of the tube, dysfunctional uterine contractility interfering with ovum or sperm transport or embryo implantation, and poor regional blood flow resulting in focal endometrial attenuation or ulceration.[17] The incidence of asymptomatic endometrial polyps in women with infertility has been reported to range from $10 \%$ to $32 \%{ }^{[18,19]}$ A prospective study of 224 infertile women who underwent hysteroscopy observed a $50 \%$ pregnancy rate after polypectomy.[20]

Metter reported that the complication rate of hysteroscopy was $1.65 \%$. When monitored by laparoscopy, the complication rate of hysteroscopy declined significantly, and reported Hysterolaparoscopy as a safe procedure. Other than mild abdominal pain, there were no major surgical or anaesthetic complications in any of our patients.

Hysterolaparoscopy has enabled therapeutic procedures like drilling in polycystic ovaries, release of adhesions, excision, aspiration, cauterisation of endometriotic cysts and endometriosis, septal resection, fimbrial cannulation, release of simple tubal mucosal blocks by repeated chromotubation, etc., apart from the diagnosis of those problems and the procedure of hysterolaparoscopy had no major complications in our study.

\section{CONCLUSION}

Diagnostic hysterolaparoscopy is an effective and safe tool in comprehensive evaluation of female infertility that can detect various structural abnormalities in multiple sites like pelvis, tubes, and the uterus in the same sitting in patients with normal ovulation and seminogram and is not associated with any major complications. Peritubal endometriosis, adnexal adhesions, septum in the uterus are correctable 
abnormalities that are unfortunately missed by routine pelvic examination and usual imaging procedures. When done by experienced hands and with proper selection of patients, hysterolaparoscopy is a definitive investigative day care procedure for evaluation of female infertility. This helps in formulating specific plan of management. Hysterolaparoscopy has a therapeutic role for application in the same sitting, enabling ovarian drilling, tubal cannulation, fimbrioplasty, adhesiolysis, Uterine septal resection, excision of chocolate cysts, cauterisation of endometrial spots, etc. and thus facilitating conception.

\section{REFERENCES}

[1] Boivin J, Bunting L, Collins JA, et al. International estimates of infertility prevalence and treatmentseeking: potential need and demand for infertility medical care. Hum Reprod 2007;22(6):1506-12.

[2] WHO Laboratory manual for the examination of human semen and sperm-cervical mucus interaction. $4^{\text {th }}$ edn. Cambridge: Cambridge University Press 1999. World Health Organization.

[3] Miller JH, Weinberg RK, Canino NL, et al. The pattern of infertility diagnoses in women of advanced reproductive age. Am J Obstet Gynecol 1999;181(4):952-7.

[4] Mol BW, Collins JA, Burrows EA, et al. Comparison of hysterosalpingography and laparoscopy in predicting fertility outcome. Hum Reprod 1999;14(5):1237-42.

[5] Jayakrishnan K, Koshy AK, Raju R. Role of laparohysteroscopy in women with normal pelvic imaging and failed ovulation stimulation with intrauterine insemination. J Hum Reprod Sci 2010;3(1):20-4.

[6] Godinjak Z, Idrizbegovic E. Should diagnostic hysteroscopy is a routine procedure during diagnostic laparoscopy in infertile women? Bosn J Basic Med Sci 2008;8(1):44-7.

[7] Tsuji I, Ami K, Miyazaki A, et al. Benefit of diagnostic laparoscopy for patients with unexplained infertility and normal hysterosalpingography findings. Tohoku J Exp Med 2009;219(1):39-42.

[8] Wallach EE. The uterine factor in infertility. Fertil Steril 1972;23(2):138-58.
[9] Brown SE, Coddington CC, Schnorr J, et al. Evaluation of outpatient hysteroscopy, saline infusion hysterosonography and hysterosalpingography in infertile women: a prospective, randomized study. Fertil Steril 2000;74(5):1029-34.

[10] Romano F, Cicinelli E, Anastasio PS, et al. Sonohysterography versus hysteroscopy for diagnosing endouterine abnormalities in fertile women. Int J Gynaecol Obstet 1994;45(3):253-60.

[11] Mooney SB, Milki AA. Effect of hysteroscopy performed in the cycle preceding controlled ovarian hyperstimulation on the outcome of in vitro fertilisation. Fertil Steril 2003;79(3):637-8.

[12] Homer HA, Li TC, Cooke ID. The septate uterus: a review of management and reproductive outcome. Fertil Steril 2000;73(1):1-14.

[13] Grimbizis GF, Camus M, Tarlatzis BC, et al. Clinical implications of uterine malformations and hysteroscopic treatment results. Hum Reprod Update 2001;7(2):161-74.

[14] Kamiński P, Wieczorek K, Marianowski L. Usefulness of hysteroscopy in diagnosing sterility. Ginekol Pol 1992;63(12):634-7.

[15] Donnez J, Jadoul P. What are the implications of myomas on fertility? A need for a debate. Hum Reprod 2002;17(6):1424-30.

[16] Pritts EA. Fibroids and infertility: a systematic review of the evidence. Obstet Gynecol Surv 2001;56(8):48391.

[17] Vollenhoven BJ, Lawrence AS, Healy DL. Uterine fibroids: a clinical review. $\mathrm{Br} J$ Obstet Gynaecol 1990;97(4):285-98.

[18] Hinckley MD, Milki AA. 1000 office-based hysteroscopies prior to in vitro fertilization: feasibility and findings. JSLS 2004;8(2):103-7.

[19] Shalev J, Meizner I, Bar-Hava I, et al. Predictive value of transvaginal sonography performed before routine diagnostic hysteroscopy for evaluation of infertility. Fertil Steril 2000;73(2):412-7.

[20] Shokeir TA, Shalan HM, EI-Shafei MM. Significance of endometrial polyps detected hysteroscopically in eumenorrheic infertile women. J Obstet Gynaecol Res 2004;30(2):84-9. 